\title{
A Report on 47th Annual Meeting of SNACC
}

\author{
Surya K. Dube ${ }^{1}$ \\ ${ }^{1}$ Department of Neuroanaesthesiology and Critical Care, All India \\ Institute of Medical Sciences (AIIMS), New Delhi, India
}

J Neuroanaesthesiol Crit Care 2019;6:305-306

The 47th Annual Meeting of Society of Neuroanaesthesiology and Critical Care (SNACC) was organized at Phoenix in Arizona from September 12 to 14, 2019. The meeting was unique in a way that it was the first stand-alone meeting since 1989 and was modeled differently than those of the past, as it was two-and-a half day event. More than 300 participants attended this meeting and it was well appreciated. The academic activity on the first day of the meeting, that is, September 12, 2019, started in the afternoon; there were three parallel sessions. The session on patient safety was moderated by Dr. Sabine Kreilinger. Drs. Karen Domino, Michael Todd, Steven Roth, and Chanannait Paisansathan discussed different aspects of patient safety in complex spine surgeries. In this session, few important topics, such as safe strategies for intubation in cervical spine injuries and postoperative visual loss, were discussed. Following the symposium, there was a workshop on basic science moderated by Drs. Ines P. Koerner and Monica S. Vavilala, and Drs. Jonathan Lifshitz, David Loane, Helen Bramlett, and Douglas DeWitt discussed about inflammasome and outcome after traumatic brain injury. The lectures in this session were about relationships between inflammatory mediators, posttraumatic sleep and outcome, sex differences in neuroinflammation, targeted temperature management, and inflammatory mediators of injury and nanopulsed laser therapy as a novel modulator of inflammatory mediators of injury after blast injury. The topics were concisely discussed.

Evidence-based Medicine Training for Academicians session was conducted by Drs. Philip Jones, Lingzhong Meng, Janet Martin, and Alana Flexman in which various aspects of conducting clinical evidence-based research were discussed. The session by the International Council on Perioperative Neuroscience Training (ICPNT) for educators and trainees consisted of two sessions. The first session was on taking the mystery out of curriculum development and focused mainly on clinicians-educators. This session was done in collaboration with the Society for Education in Anesthesia (SEA). The second session was regarding neuroanesthesia essential skills boot camp. This session had lectures and hands-on sessions on scalp blocks for awake craniotomy, cervical plexus block and airway regional anesthesia, transcranial Doppler (TCD),
Address for correspondence Surya K. Dube, MD, DM, Department of Neuroanaesthesiology and Critical Care, 7th Floor, Neurosciences Center, All India Institute of Medical Sciences (AlIMS), New Delhi, India 110029 (e-mail: surya.dube@yahoo.co.in).

near infrared spectroscopy (NIRS), motor evoked potential (MEP) raw and processed electroencephalography (EEG). In this session, the participants had hands-on experience of different neuromonitoring methods and they had opportunity to learn certain practical tips about different monitoring methods. The day concluded with welcome reception and residents' and fellows' reception.

On the second day, the meeting started with the Maurice Albin Keynote lecture by Dr. Amy Wagner that was about "Rehabilomics Research titled "Towards a Precision Medicine Approach to Optimizing Function after Acquired Brain Injury." Following that, there was a session on brain-heart crosstalk coordinated by Drs. Monica Vavilala and Vijay Krishnamoorthy. It was an informative session about the cardiovascular manifestations of cerebral injury. The next session was on "Women in Neuroanesthesiology and Neuroscience Education and Research (WINNER)" focusing on the "career advancement for women in perioperative neuroscience: barriers and opportunities," where Drs. Karen Domino, Kristin Engelhard, Deb Culley, and Monica Vavilala shared their views on this issue. A special lunch quiz session "Neuroanesthesiology Review Fun! " was organized for residents and fellows simultaneously. This quiz was moderated by Drs. Suneeta Gollapudy, Jacqueline M. Morano, and Shobana Rajan. The next session was on the future of neuromonitoring and its use in neuroanesthesia and neurointensive care. This session was moderated by Drs. Andrew Kofke and Martin Smith. The different topics discussed were multimodal monitoring, noninvasive optical monitoring of cerebral blood flow/cerebral metabolism $\left(\mathrm{CBF} / \mathrm{CMRO}_{2}\right)$, critical closing pressure, autoregulation, neurophysiologic signatures for brain injury classification, and prediction. The final session on the second day was on "Going off the Rails: What Happens to CBF during GA and Why" by Dr. Joseph Fisher. The day ended with The William Young Fundraiser Dinner that provided an excellent opportunity of interaction between the participants. The dinner ended with much fun and fare.

The third day started with four problem-based learning discussion (PBLD), that is, carotid endarterectomy, posterior cervical surgery, subarachnoid hemorrhage, and deep brain stimulation. Each PBLD was of 1-hour duration and
DOI https://doi.org/ $10.1055 / \mathrm{s}-0039-3400190$ ISSN 2348-0548.
Copyright $@ 2019$ Indian Society of Neuroanaesthesiology and Critical Care
License terms

()(1) $\Theta \circledast$ 
had active participation of the moderators and participants. The participants had an opportunity to know the practical tips about each topic. First general session of the day was "Burst Suppression-New Evidence" where Drs. Brandon Westover, Max Kelz, and James Sleigh discussed the newest discovery in burst suppression. Following the session, in the business meeting, the new board members were introduced and Dr. Deepak Sharma took over as the new president of SNACC. After this session, the award presentations including the travel awards and the presentation of the John D. Michenfelder New Investigator winner started. Additionally, the first Best of Meeting oral presentation awards in basic and clinical/translational neuroscience were also presented this year. Dr. Jason Chui got the clinical/translational neuroscience best of meeting oral presentation award. Drs. Sanket Agrawal, Wooheon Thomas, That Nyan Lwin, Ayako Oi, Valerie Verdun, Li-Min Zhang, and Anjum Parkar were awarded the travel grant awards this year. Dr. Boris Heifets received the William L. Young neurosciences research award for his research on "Ketamine therapy for reducing perioperative risk in depressed patients." In the post lunch session, there was a point-counterpoint debate between experts on "Operating Room (OR) to Intensive Care Unit (ICU) Hand-off and Direct Recovery in ICU for Neurosurgical Patients" (Drs. Bhiken Naik: pro; and Arthur Lam: con) and "EEG Monitoring under Anesthesia: Necessary or Nuisance?" (Drs. Paul Garcia: pro; and Piyush Patel: con). In the next session, Dr. Abhijit Lele presented the latest publication in international external ventricular drain (EVD) guidelines and management with the talk entitled EVD practice-"Are We on the Same Page?" The last session of the meeting was about the "Journal of Neurosurgical Anesthesiology (JNA) Year in Review" by Dr. Martin Smith. Both the second and third days had poster discussion sessions. Beside this, there were poster sessions where delegates from various parts of the world presented their research work. This year, the poster presentation included both e-posters and physical poster presentations. The poster sessions were nicely coordinated. Finally, the meeting concluded with closing remarks by Dr. Deepak Sharma, the new president of SNACC.

\section{Conflict of Interest}

None declared. 